\title{
Perbandingan Performansi 4 Variasi Siklus Kompresi Uap 2 Tingkat
}

\section{Siwan Ediamanta Perangin-angin ${ }^{1,}$, Himsar Ambarita ${ }^{1}$, Waldemar Naibaho ${ }^{2}$, Parulian Siagian $^{2}$, Marhiras Sitanggang ${ }^{3}$, Libianko Sianturi ${ }^{3}$}

\author{
${ }^{1}$ Sustainable Energy Research Centre, Universitas Sumatera Utara, Jl. Almamater Kampus \\ USU, Medan 20155 Indonesia \\ ${ }^{2}$ Program Studi Teknik Mesin, Fakultas Teknik, Universitas HKBP Nommensen, Medan 20234 \\ ${ }^{3}$ Program Studi Teknik Elektro, Fakultas Teknik Universitas HKBP Nommensen, Medan 20234 \\ *edi_siwan@yahoo.com
}

\begin{abstract}
The existence of Air Conditioning (AC) is inseparable from aspects of everyday life. Air Conditioning makes use of the thermodynamic principle of the vapor compression cycle. COP is a parameter to see the performance of the cooling engine. In this study, one way to increase the COP of a Cooling engine was to modify a 1-stage cycle to a 2-stage cycle. This paper examines the comparison of a two-stage vapor compression cycle model with several variations. This comparison uses the ASPEN PLUS V10 software to see the performance of each variant. For the working fluid (Refrigerant) used is $R-32$. From the simulation results, variant no III shows a higher COP value than the other variants.
\end{abstract}

Keywords : Performance, Steam Compression, 2 Levels

\section{PENDAHULUAN}

Pengkondisian udara adalah suatu hal yang tidak dapat terlepas dari kehidupan modern saat ini. Penerapan ini dapat kita lihat di berbagai aspek kehidupan [1]. Mulai dari rumah tangga, perkantoran, tempat umum, pabrik atau pun tempat-tempat lainnya. Hal ini berkaitan dengan tingkat kenyaman dari orang-orang yang didalamnya. Faktor ini tidak terlepas dari perubahan iklim yang makin ekstrim pada saat ini. Hampir semua negara berdampak oleh perubahan iklim tersebut. Salah satu factor perubahan iklim tersebut adalah meningkatnya emisi karbon $\mathrm{CO} 2$ yang merusak lapisan ozon yang dipengaruhi oleh banyak faktor-faktor yaitu Pembakaran hutan [2], gas buang industri, pemanfaat bahan bakar yang tidak ramah lingkungan dan tidak efisiensinya suatu peralatan yang menyebabkan energi yang dihasilkan terbuang percuma. Terkhusus penggunaan Pengkondisian Udara (AC) yang sangat tinggi di negara-negara maju maupun yang sedang berkembang [1]. Hal ini yang memacu pengembangan penelitian tentang pengkondisian udara yang semakin maju, agar mendapatkan produk yang mempunyai kinerja tinggi dan hemat daya yang berefek kepada dampak lingkungan.

Perkembangan dunia penelitian tentang system pengkondisian udara semakin maju. Banyak penelitian eksperimen maupun secara simulasi menunjukkan dengan memodifikasi, pengaturan suhu dan tekanan siklus kompresi uap dapat meningkatkan COP (Coefficient of Performance) suatu siklus [1,3]. Contoh modifkasi Siklus Kompresi Uap bias dilakukan dengan menambahkan Alat Penukar Kalor Internal yang menyingungkan aliran fluida kerja (Refrigeran) dari keluar katup ekspansi dengan aliran keluar kondensor [4]. Hal ini bertujuan untuk menurunkan temperature masuk ke kompresor. Hal ini terbukti meningkatkan nilai dari COP dari Mesin pendingin sebesar 9.02\% dengan jenis Refrigran R410a [5]. Penlitian yang lain juga menunjukkan penggunaan Alat Penukar Kalor Internal pada siklus Pendingin karbon dioksida trankristis dengan expander meningkatkan kapasitas pendingin spesifik dan COP 
sebesar 17\%. Cara yang lain dapat menggunakan menigkatkan siklus dari 1 tingkat menjadi 2 tingkat. Secara teoritis mengubah siklus kompresi uap 1 tingkat menjadi 2 tingkat, terbukti meningkatkan performansi dari suatu siklus kompresi uap atau COP meningkat sebesar 10-15\%[6]. Yang membedakan siklus 1 tingkat dengan 2 tingkat adalah, siklus 2 tingkat mempunyai 2 titik tekanan yang dihasilkan dari 2 kompresor. Sedangkan untuk yang 1 tingkat hanya 1 tingkat tekanan atau 1 kompresor saja. Untuk system Siklus Kompresi Uap 2 tingkat mempunyai banyak variasi model [1-2], artinya penambahan komponen-komponen pendukung selain dari penambahan jumlah kompresor. Hal ini bertujuan untuk merekayasa siklus agar mendapatkan Siklus dengan Kinerja yang lebih tinggi atau COP yang lebih tinggi, dilihat dari penurunan Daya Kompresor dan Efek Pendinginan pada siklus tersebut [3].

Hal ini yang akan diteliti pada tulisan ini untuk melihat perbedaan kinerja dari beberapa varian siklus kompresi uap 2 tingkat dengan parameter-parameter masukan yang disesuaikan dengan pengujian siklus kompresi uap 1 tingkat. Metode yang digunakan dalam penelitian ini adalah metode simulasi. Software yang dipakai adalah ASPEN PLUS V10 yang berfungsi untuk menggambarkan siklus termodinamika sesuai dengan varian yang akan disimulasikan. Hasil yang akan didapat adalah Daya Kompresor Panas yang diserap Evaporator dan Panas yang dilepaskkan oleh Kondensor. Parameter inilah yang akan menentukan nilai dari COP dari Siklus tersebut.

\section{METODE PENELITIAN}

Dalam penelitian ini menggunakan Sofware ASPEN PLUS V10. Proses simulasi di Aspen membutuhkan parameter-parameter input sebagai data masukan untuk menjalankan simulasi. Penelitian ini mempunyai parameter input yaitu, Tekanan Kondesor (Pk): 320 Psi,Tekanan Evaporator (Pe): 110 Psi, Tekanan Median (Pm): 170 Psi dan Laju aliran Masa (m ): $0.005 \mathrm{~kg} / \mathrm{s}$. Untuk proses simulasi diperlukan proses penggambaran siklus dengan memasukkan komponen-komponen yang diperlukan. Untuk fluida kerjanya dipilih Refrigeran R-32. Proses simulasi dapat dilihat pada gambar 1 . Setiap varian siklus kompresi uap 2 tingkat mempunyai komponenkomponen yang berbeda. Diagram prosesnya dapat di lihat pada gambar 1.

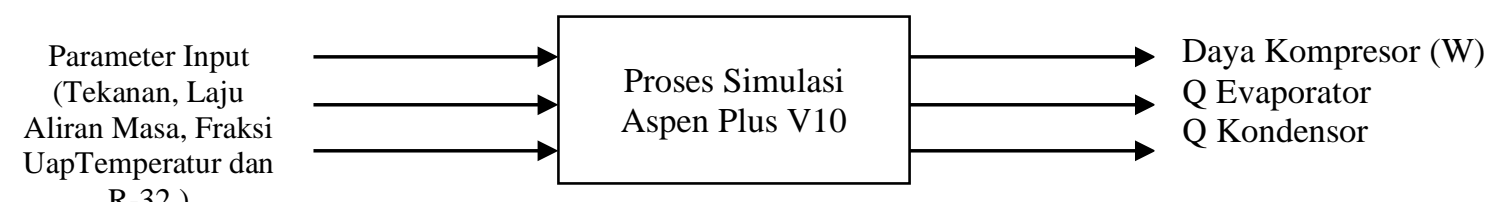

Gambar 1. Proses Simulasi

Penelitian ini memvariasikan 4 model siklus kompresi uap 2 tingkat. Pada gambar 2 adalah $p$ - $h$ dari setiap varian siklus kompresi uap 2 tingkat.

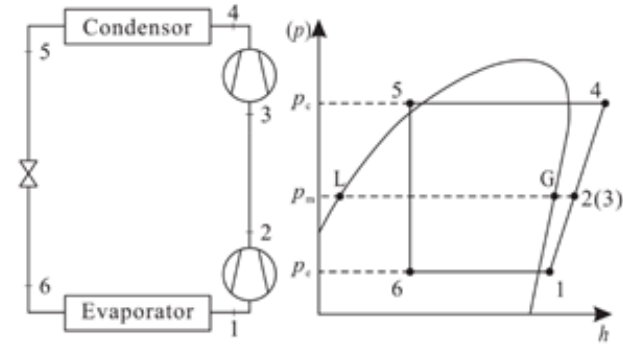

(varian I)

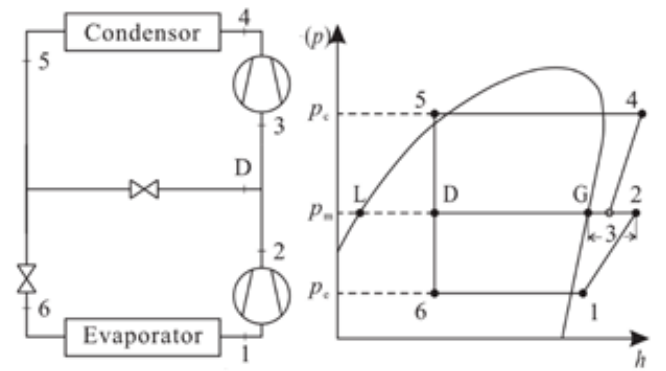

(varian II)

Gambar 2. Varian I dan Varian II siklus Kompresi Uap 2 tingkat 
Pada gambar 2 SKU 2 tingkat varian I dan Varian 2 mempunyai diagram $p$-h yang cukup mirip. Yang membedakannya adalah adanya tambahan Katup Ekspansi pada aliran keluar Kondensor (titik 5) yang satu menuju Evaporator (titik 6) yang satu lagi menuju titik D, dimana aliran refrigerant keluar kompresor 1 (Titik 2). Berbeda dengan varian I yang hanya mempunyai 1 katup ekspansi.
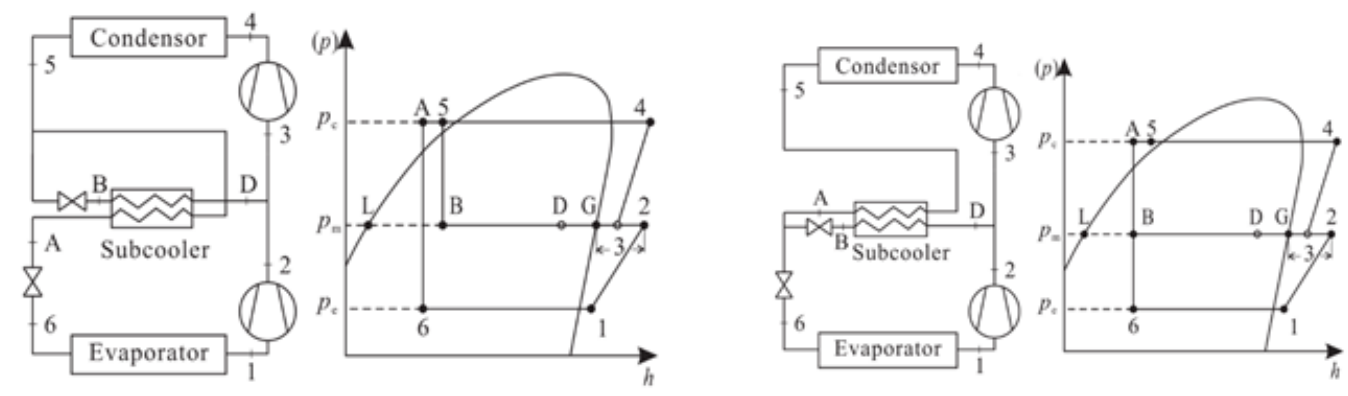

Gambar 3. Varian III dan Varian IV siklus Kompresi Uap 2 tingkat

Pada gambar 3 adalah skema dan diagram $p$ - $h$ untukvarian III dan Varian IV. Pada SKU 2 tingkat varian berbeda dengan varian I dan II. Pada varian III dan varian IV, siklus mempunyai komponen tambahan yang dinamakan Subcooler. Tetapi untuk untuk varian III dan IV mempunyai perbedaan, di mana untuk varian 3 aliran bercabang setelah keluar dari Codensor (titik 5), untuk varian IV aliran bercabang keluar titik 5 setelah melewati Subcooler. Hal ini menyebabkan karakteristik diagram $p$ - $h$ untuk masing-masing varian.

Secara umum persamaan yang digunakan untuk menganalisa kinerja dari Siklus Kompresi Uap adalah :

Untuk Daya Kompresor adalah :

$$
\dot{W}_{c}=\dot{m}_{1}\left(h_{2}-h_{1}+h_{3}-h_{4}\right)
$$

Untuk panas yang dibuang oleh Kondensor adalah :

$$
Q_{c}=\dot{m}\left(h_{4}-h_{5}\right)
$$

Untuk analisis $Q_{c}$ atau Panas yang dibuang Kondesor setiap varian berbeda-beda, tergantung dari grafik $p$ - $h$ masing-masing varian.

Untuk Panas yang diserap oleh Evaporator adalah :

$$
Q_{e}=\dot{m}\left(h_{6}-h_{1}\right)
$$

Sama halnya dengan $Q_{c}, Q_{e}$ Panas yang diserap evaporator juga berbeda sesuai dengan dari grafik $p$ - $h$ masing-masing varian.

Untuk Coefficient of Performance (COP) siklus adalah

$$
\mathrm{COP}=\frac{Q_{e}}{W_{c}}
$$

Program Aspen Plus memungkinkan untuk menyelesaikan persamaan termodinamika untuk siklus kompresi uap 1 tingkat maupun modifikasi lainnya.

\section{HASIL DAN PEMBAHASAN}

Gambar 4 menampilkan pemodelan Siklus Kompresi Uap 2 tingkat dengan 4 variasi yang ada di Aspen Plus. Parameter ini menunjukkan nilai dari tekanan, temperatur dan fraksi uap di setiap titik. Terlihat Tekanan Evaporator (Pe), Tekanan Median (Pm) dan Tekanan Kondensor (Pk) laju aliran masa juga sama. 


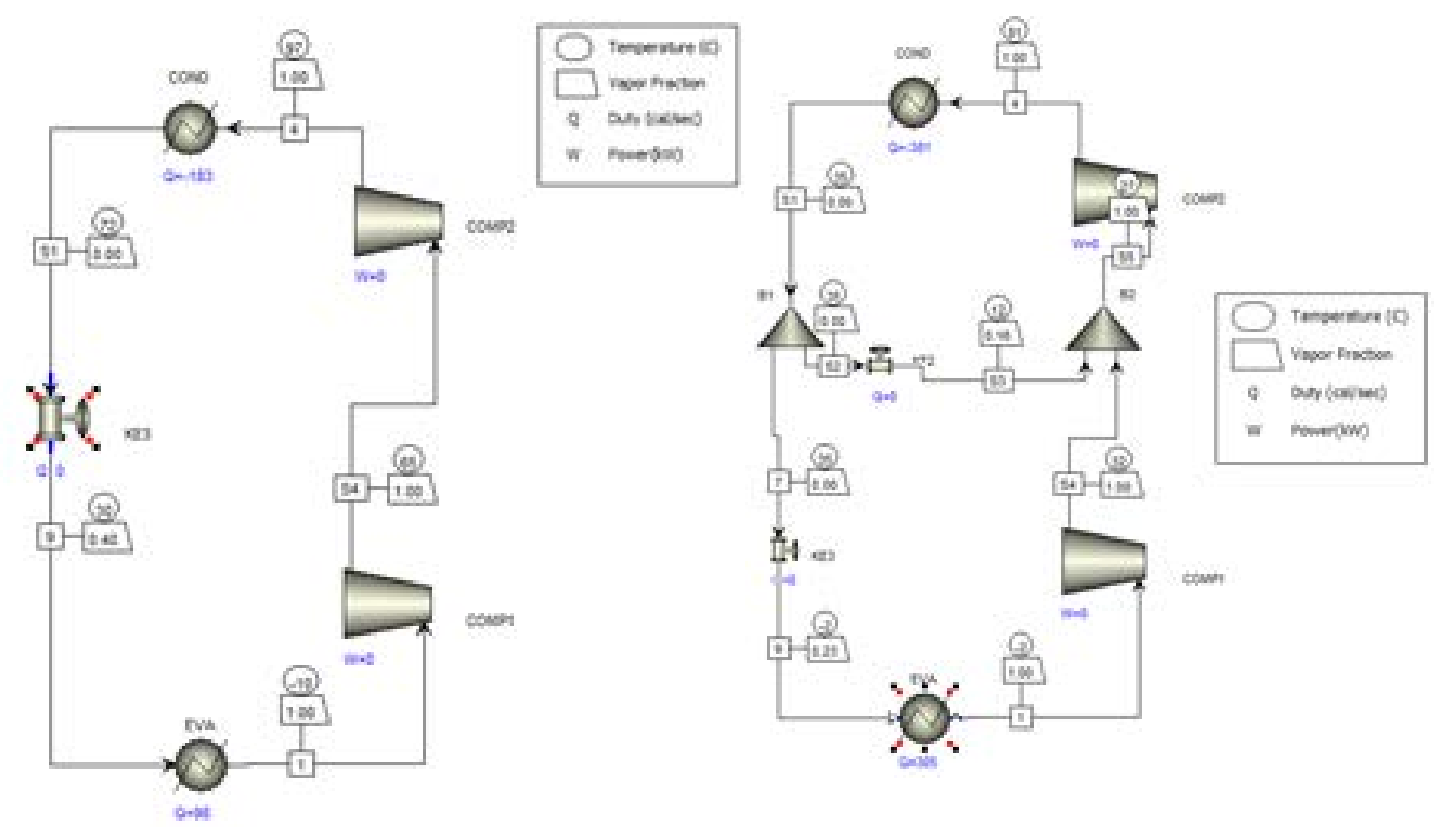

Gambar 4. Pemodelan SKU 2 tingkat Varian I dan Varian II

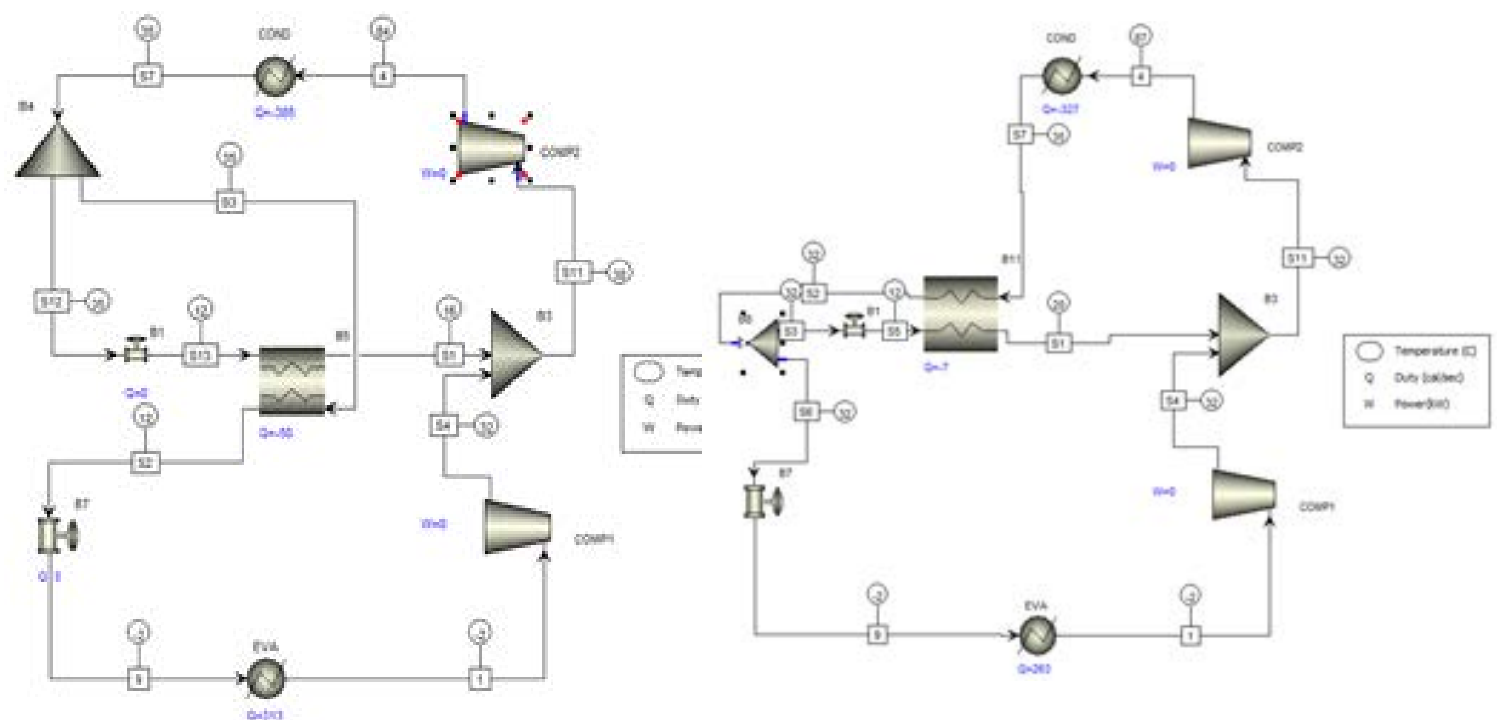

Gambar 5. Pemodelan SKU 2 tingkat Varian III dan Varian IV

\subsection{Hasil Perbandingan Performansi SKU}

Table 1 menunjukkan hasil perbandingan performansi dari setiap varian SKU 2 tingkat. Daya kompresor setiap Varian dijumlahkan karena setiap siklus menggunakan 2 kompresor. Untuk Qc (panas yang diserap oleh kondensor bertanda minus (-) artinya panas dilepaskan atau dibuang kelingkungan. Tanda positive $(+)$ artinya panas diserap oleh system. COP didapatkan dari perbandingan Panas yang diserap oleh Evaporator (Qe) berbanding Daya Kompresor (Wc). 
Tabel 1. Perbandingan Performansi SKU 2 tingkat Varian I sampai Varian IV

\begin{tabular}{|c|c|c|c|c|c|c|c|}
\hline \multirow[b]{2}{*}{ No } & \multirow[b]{2}{*}{ Varian } & \multicolumn{3}{|c|}{ Daya (KW) } & \multirow{2}{*}{$\begin{array}{c}\text { Q (KW) } \\
\text { Evaporator }\end{array}$} & \multirow{2}{*}{$\begin{array}{c}\text { Q (KW) } \\
\text { Kondensor }\end{array}$} & \multirow[b]{2}{*}{ COP } \\
\hline & & $\underset{\text { I }}{\text { Comp }}$ & $\begin{array}{l}\text { Comp } \\
\text { II }\end{array}$ & Total & & & \\
\hline 1 & SKU Multi Stage I & 0.25781 & 0.09902 & 0.3568309 & 0.410533 & -0.767365 & 1.150497 \\
\hline 2 & SKU Multi Stage II & 0.11992 & 0.19533 & 0.31525 & 1.27853 & -1.59378 & 4.055607 \\
\hline 3 & SKU Multi Stage III & 0.10313 & 0.19824 & 0.301369 & 1.31663 & -1.612 & 4.36883 \\
\hline 4 & SKU Multi Stage IV & 0.10073 & 0.16906 & 0.269792 & 1.09928 & -1.37053 & 4.074546 \\
\hline
\end{tabular}

\subsubsection{DayaKompresor}

Dari hasil simulasi, menunjukkan Daya Kompresor SKU 2 tingkat Varian I menunjukkan komsumsi daya yang tinggi dibandingkan varian lain yaitu sebesar 0.3568 KW. Hal ini menyebabkan pemakain energi yang besar dibandingkan yang lain dengan kondisi yang sama. Sebaliknya SKU 2 tingkat varian IV menunjukan komsumsi daya yang lebih rendah dari pada varian yang lainnya.

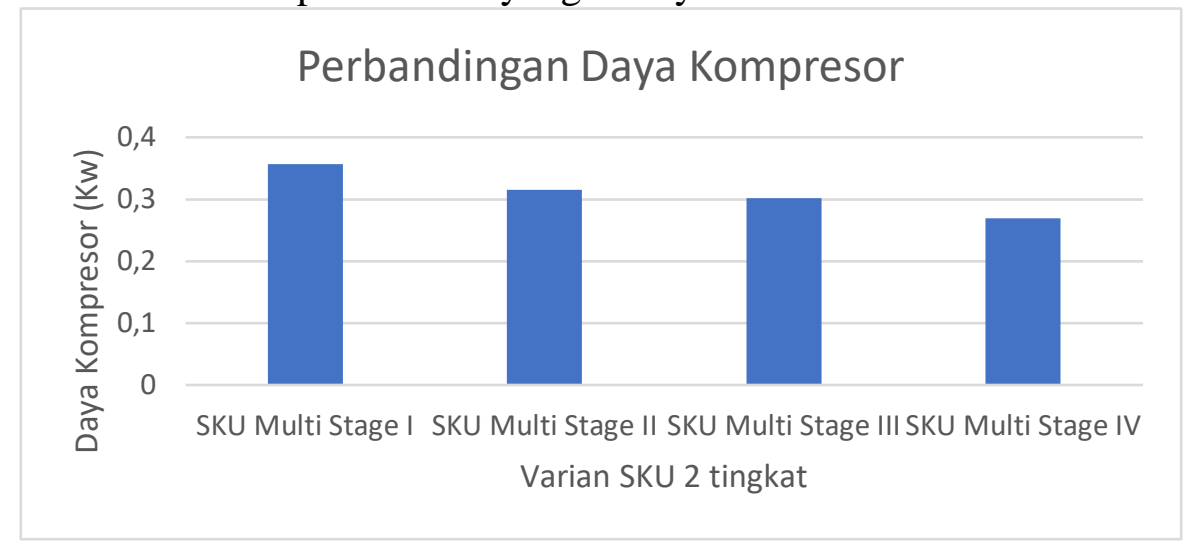

Gambar 6. Perbandingan Daya Kompresor SKU 2 tingkat

\subsubsection{Panas yang diserap Evaporator}

Dari hasil simulasi, menunjukkan Panas yang diserap Evaporator (Qe) SKU 2 tingkat, Varian I menunjukkan Qe yang lebih rendah dari pada varian lain yaitu sebesar 0.4105 KW. Varian 3 munjukkan Qe yang lebih tinggi dari pada varian yang lain sebesar $1.31663 \mathrm{KW}$.

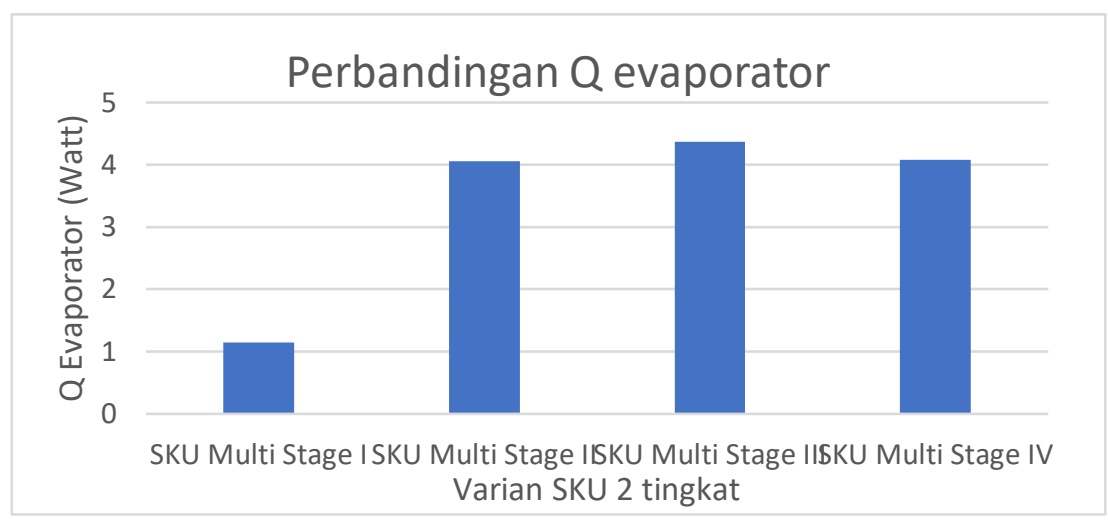

Gambar 7. Perbandingan Daya Kompresor SKU 2 tingkat 


\subsubsection{Panas yang dibuang Kondensor}

Dari hasil simulasi, menunjukkan Panas yang dibuang Kondensor SKU 2 tingkat Varian I menunjukkan Panas yang dibuang Kondesor (Qc) lebih rendah dibandingkan varian lain yaitu sebesar $0.767365 \mathrm{KW}$. Varian III Qc lebih tinggi dari pada varian yang lain sebesar1.612 KW.

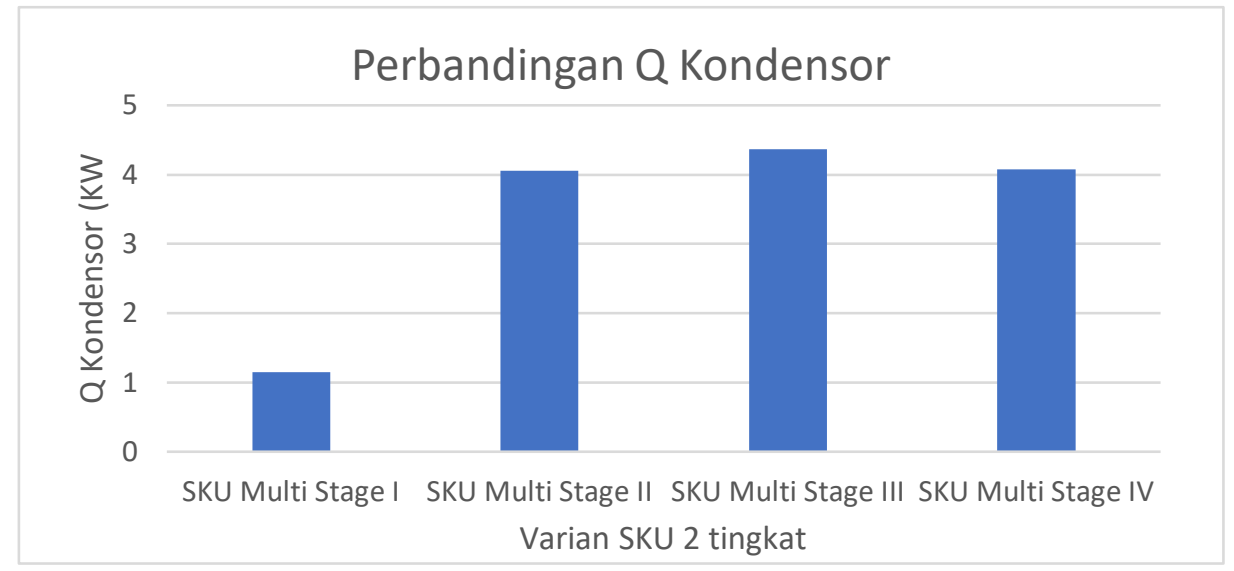

Gambar 8. Perbandingan Daya Kompresor SKU 2 tingkat

\subsubsection{COP}

Dari hasil simulasi, menunjukkan COP SKU 2 tingkat Varian I lebih rendah dibandingkan varian lain yaitu sebesar 1.150497. Varian III menunjukkan nilai COP yang lebih tinggi dari pada Varian yang lain sebesar 4.36883.

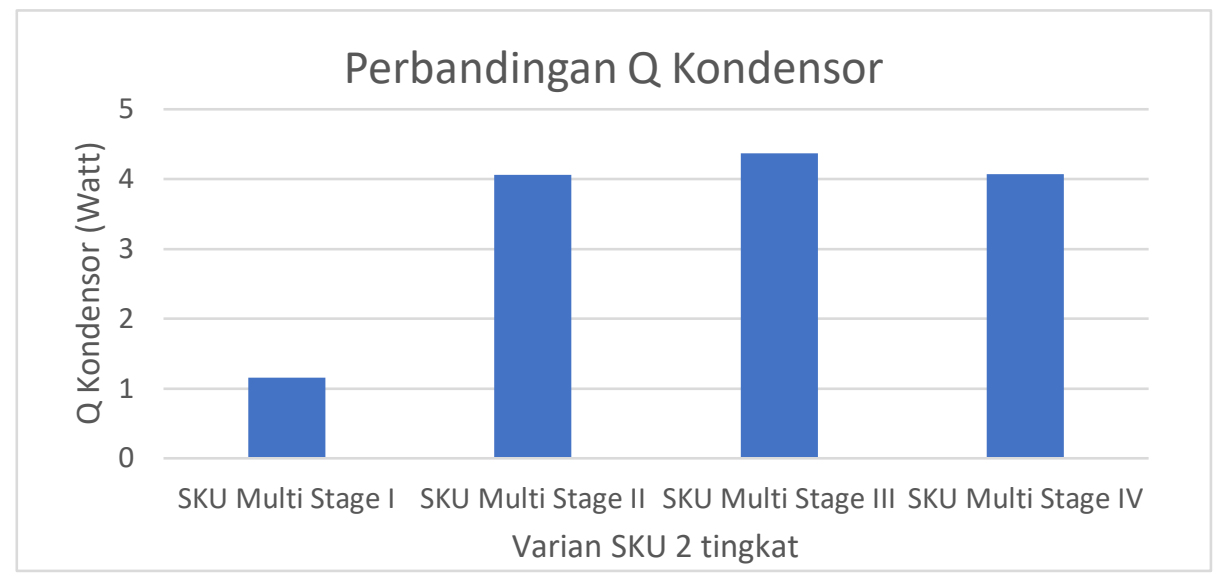

Gambar 9. Perbandingan Daya Kompresor SKU 2 tingkat

\section{Kesimpulan}

Dari hasil perbandingan simulasi ASPEN PLUS Siklus Kompresi Uap 2 tingkat Varian I sampai varian IV maka didapat kesimpulan :

- SKU 2 tingkat Varian III mempunyai nilai COP yang lebih tinggi dari pada 3 varian yang lainnya. Sedangkan Varian I mempunyai nilai COP yang paling rendah diantara 3 varian lainnya 


\section{DAFTAR PUSTAKA}

1. Chasik Park, Hoseong, Yunho Hwang. 2015 Recent Advances In Vapor Compression Cycly Technologies. Science Direct 118-134

2. Mahdi Deymi-Dastebayaz, Saeed Maddah, Elmira Fallahi. 2019. Internasional Journal Of Refrigeration. 106 (2019) 7-17

3. D.L Karelin, A.V. Boldyrev, A.M BelouSov. 2017. International Conference On Industrial Engineering. Procedia Engineering 206 (2017) 1488-1496

4. Djuanda. 2018. International Conference on Thermal Science and Technology, 020008-1-020008-7.

5. Zhang Z, Tian L, Chen Y, and Tong L. 2014. Entropy 16 5919-5934.

6. Ambarita H, Nasution D M, Gunawan S and Nasution A H 2017 IOP Conf. Series: Material Science and Engineering180 012027 